\title{
Consequences of a Spectacle? Alleged Match-Fixing in the National Basketball Association Western Conference Finals of 2002
}
Authors' contribution:
A) conception and design of the study
B) acquisition of data
C) analysis and interpretation of data
D) manuscript preparation
E) obtaining funding

\author{
Łukasz Muniowski \\ University of Warsaw, Poland, Warsaw
}

ABSTRACT

No major professional sports league epitomizes Guy Debord's idea of the spectacle more than the NBA. The league was the first to understand the importance of highlights and global expansion, and participated in creating the first branded superstar in Michael Jordan. Naturally there are some controversies surrounding the rise to its present-day status, like the (supposedly) fixed 1985 draft or Michael Jordan's (supposedly) enforced first retirement. One of the most controversial events in recent league history took place during Game Six of the 2002 Western Conference Finals between the Los Angeles Lakers and the Sacramento Kings. A lot of controversial calls by the referees allowed the Lakers to win the game and eventually the series. As the Lakers were about to get eliminated, the league officials allegedly encouraged referees to force a Game Seven. The problem with the allegations was that they were made public by former referee Tim Donaghy, who himself used to bet on games. David Stern, the league's former commissioner was referring to Donaghy's gambling addiction as the reason for the falsity of his statements. My paper uses the game in question as a case study in order to present the spectacular aspects of the NBA.

KEYWORDS

spectacle, Debord, basketball, Lakers, NBA

\section{Introduction}

Bad calls determine the outcomes of plays, games and seasons, while bad-officiating is an almost integral part of sports. Human error is always possible during a sporting event. Athletes have off-days, so do match officials. The paper draws on the concept of "spectacle", as understood by French philosopher Guy Debord. Brian Tuohy, the author of numerous books on game fixing, observes that "at certain critical junctures, storylines become more important than the purity of the contest" (2010, p. 160). This paper argues that this is exactly what happened during the 2002 National Basketball Association (henceforth the NBA) Conference Finals. It will begin by briefly introducing the reader to the idea of the "spectacle" and its connection with the NBA. It will then continue by presenting and analysing the problematic decisions themselves. Then, it will focus on the reasons why accusations of "fixing" might be justified, and on the narratives surrounding such accusations. 
The bad decisions during the game were so blatant that they became the basis of various conspiracy theories, suggesting that the result was fixed in some way or the other. Ten years after the series, journalist Matt Gallagher still accused the officials of robbing the Kings of their first NBA Finals appearance in over forty years (2012). William Dayton of Roundball Daily called the 2002 Kings-Lakers "one of the most lopsided officiated series in sports history" (2010). Chris Webber, the Kings' best player at the time, admitted that during his career he played in one game in which "something smelled weird about the whole situation", with the clear suggestion he was referring to Game Six of the series (Putterman 2016).

In 2002 there were, naturally, many other badly-officiated games in other sports. The football World Cup in South Korea and Japan, for example, saw the unlikely rise of the South Korean National Team, which made it all the way to the semi-finals, eliminating heavy favourites Italy and Spain. Both outcomes were controversial and overshadowed by referee scandals. In the first game, against Italy, Ecuadorian referee Byron Moreno allowed the Koreans to play extremely hard. In South Korea's next game Egyptian referee Gamal AlGhandour also ignored the hosts' fouls, but more notably did not allow two valid goals scored by Spain. The Koreans did their fair share to win their games, but it is doubtful they would have done so without the referees' help.

The NBA is the preeminent men's professional basketball league in North America, and is widely considered to be the premier men's professional basketball league in the world. As other leagues, this also has had its fair share of scandals and conspiracy theories. The case study here focuses on Game Six of the 2002 Western Conference Finals between the Sacramento Kings and the Los Angeles Lakers. Internet searches around the game and the term 'fixed' reveal around 135,000 sites referring to the event. The Kings came into the game leading the series 3-2. The team that would have won would have played in the NBA Finals against a much worse opponent from the Eastern Conference. At the beginning of the fourth quarter the sixth game of the series was tied 75:75, but the referees called a couple of questionable fouls against the Kings in the final 12 minutes. The Lakers were allowed to shoot 27 free throws in the quarter alone - often teams do not get that much shots during the course of the whole game - made 21, added just five baskets from the field, and ultimately won 106:102. The Lakers won the next game in overtime and advanced to the finals, which they easily won.

Despite the amount of contemporary suspicions and allegations, it is almost impossible to prove that the game was actually fixed. ${ }^{3}$ Basketball is a sport based on repetition, meaning a team needs to make baskets continuously to succeed. The game of basketball is 48 minutes long (plus time-outs), and a shot clock forces a team to make a shot within 24 seconds. The giant screens show replays immediately after plays, usually from multiple angles, so bad calls are quickly exposed. This can bias players, fans and coaches against the three officials working the court during the game. Even when discussing the titular game, despite the Lakers getting 27 free throws, they still had to make those shots in order to win, which required at least some amount of skill on the part of the players.

\section{The NBA and Spectacle}

The NBA, America's most expanding and globally popular professional league (Groves 2015), has had its fair share of controversies. The best-known include the (alleged) rigging of the 1985 NBA Draft in New York Knicks' favour and Michael Jordan's (allegedly) forced 1993 retirement. Even during the 2016 NBA Finals some observers accused the league of an attempt at prolonging the series by suspending a key player of the Golden State Warriors for Game Five (SI Wire 2016). That was an elimination game for their opponents, the Cleveland Cavaliers, and thanks to the player's absence, the team from Ohio was able to shift the momentum and go from 1:3 to 4:3, ultimately winning the finals. Conspiracy theorists pointed out that the player had committed worse offences in that year's playoffs, yet it was only in the finals that he was punished

\footnotetext{
${ }^{3}$ For further reading, see: Figone, A.J., Cheating the Spread: Gamblers, Point Shavers, and Game Fixers in College Football and Basketball, Urbana, IL: University of Illinois Press, 2012; Figone, A.G., 'Gambling and College Basketball: The Scandal of 1951', Journal of Sport History, vol. 16, no. 1, Spring 1989, pp. 44-61.
} 
with a suspension. The Warriors' win would have capped off a historical season, as the team won an NBArecord 73 regular season games.

The choice of the NBA for this paper has been made because of its popularity. In his Forbes article, Roger Groves claims that its global sovereignty is already a fact, but it should dominate domestically, as NBA is able to generate the most revenue with low operating costs (Groves 2015). Simultaneously, according to the 2016 Harris Poll, the NBA is behind college football and auto-racing in popularity, as only 5\% of Americans call it their favourite sports league (Gaines 2016), which may put Groves' predictions in doubt. These opposing opinions remind us that professional sport disciplines are involved in a constant struggle for the attention of the spectator. Even though the league may struggle domestically, NBA has gone out of its way to become the most popular American professional sports league in the world, as it has been for several years. Its success may be attributed to the willingness to stage games in various countries outside North America before and during the regular season, as well as moving some games to earlier hours in order to allow people on the other side of the globe to watch them live. Basketball is also more popular globally than baseball or American football, as it has a rich history in countries as various as Australia, Spain or Lithuania.

Unlike European leagues, which are based on the relegation-promotion system causing a constant rotation of teams, the American league system is more about sustainability. The salary cap allows teams from small markets and big cities to spend the same amount of money on player salaries, penalizing those that go over the cap. The draft gives the worst teams during a particular season the best chance of getting the most promising young players who have not yet signed professional contracts - the worse the team, the better the chance of getting the best player and rebuilding around him. Both, the cap system and the draft, are intended to keep the league interesting and competitive. More competitive teams make for entertaining outcomes, which then can be connected to form entertaining storylines. Nicole Aschoff claims that "we are all storytellers" (2015, p. 1). Modern society is built on stories of personal or collective success, development, loss, etc. Most stories are small, insignificant, while others become universal and important. Aschoff characterizes the latter as simply "big stories", which "get us out of bed in the morning and remind us where we are going in life" (2015, p. 1). These are universally acclaimed and internalized, as they provide motivation to simply live our lives. Aschoff stresses the importance of such stories in sustaining the current capitalist order, but her reasoning is also applicable to something she ignores in her work - professional sports.

While sports also plays a part in sustaining that order, if only by providing entertainment and a break from what can be characterized as "the everyday struggle," sports fans often fall victim to big stories. The city of Cleveland's 52 year championship-drought, which actually should not have had any influence on the lives of the city's inhabitants, was narratively presented as a type of curse, which, once lifted, would finally allow them to feel actual joy. Dan O'Sullivan stresses that this storyline reduced Cleveland to "a hoary sports cliché", when there were other pressing economic and social issues that were, and still are, more important to address (2016). Cleveland's quest to brake the "curse,"'as well as Warriors" historical season are examples of big stories, which are clearly connected with today's media culture and Guy Debord's idea of spectacle.

Big story-lines and media culture often focus on major sports spectacles. In his seminal book Society of the Spectacle Guy Debord claims that "all that once was directly lived has become mere representation" (1995, p. 1). Debord implies that what we refer to as reality is just a representation of something that once was real, but is now hidden under layers of images, connotations and commercials. Because of the separation between actual objects and their representations we are left with nothing more than just notions of feelings, thoughts, events, and people. Even though they bear a certain resemblance to actual things, the feelings, events, etc., are never real. Debord's theory is often applied solely to mass media.

However, the spectacle is about more than representation, although that seems to be its key notion. It is not possible without understanding the notions of alienation, social practice, capitalism and commodities. The worker, alienated from other workers, but also from his products, is hardwired to crave products created by other, alienated workers. This vicious circle, which is also the cause of oppression, is unbreakable in the modern capitalist society. Debord was a member of the Situationist International - an international collective of rebels and revolutionaries, who combined "postsurrealist ideas about art, Marxian concepts of alienation, an attempt to recover a forgotten revolutionary tradition, millenarianism, and plain refusal of the world 
combined with a desire to smash it" (Greil 2002, p. 18).

However, Debord did not see the connection between spectacle and sports, and referred to competitive sports as a "paltry contest" incapable "of arousing any truly playful feelings" (1995, p .40). More recently, Douglas Kellner has pointed out that sports is "a largely untheorized and underrated aspect of the society of the spectacle". According to Kellner the sports version of the spectacle is a somewhat "unholy alliance between sports celebrity, commercialism, and media spectacle" (2001, p.38). In the case of the sports spectacle the creators are generally the leagues themselves, even though they act under the influence of sponsorship deals and spectatorship. American leagues like the NFL (National Football League), the NHL (National Hockey League) or the NBA have almost complete control over the product they sell and with such control there has always been space for manipulation. When reporting about former referee Tim Donaghy's hearings in July of 2008, Tuohy writes: "Donaghy told federal investigators that the NBA intentionally alters the outcomes of their own games for ratings and money" (2010, p. 224). This was a clear inference of match-fixing but the FBI did not investigate the league because it is not illegal to do that. During a presentation on the Western Economics Association conference in Seattle, sports law analyst Ryan Rodenberg explained that no federal law prohibits an American sports league from manipulating "their own contests to artificially inflate consumer interest and revenue potential. So long as such manipulation has no nexus to gambling, the rigging of game outcomes or individual events therein is legal" (The Wages of Wins Journal 2013). This suggests that even when accusations of fixing games can be proven, there is nothing that can be done to punish those involved.

\section{Game Six - Importance, Analysis and Questionable Calls}

The 2002 Sacramento Kings are probably the best team in the franchise's history. They finished the regular season with 61 wins and 21 losses - the best in the league at that time. Even before the initial series, there were justified reasons for hatred between them and the Los Angeles Lakers. The most important was both teams' close proximity to each other, as both are situated in California. Despite being the fourth biggest city in the state, Sacramento, not Los Angeles, is the capital of California. Because of that there are some animosities between the inhabitants of the cities, which were capitalised on inter alia by Lakers coach Phil Jackson, who referred to Sacramento as "semi-civilized", "redneck in some form or fashion" and a "cow town" (Cary 2015). Jackson's disdain for the city may or may not have been genuine, but his interviews were entertaining and gave the press something to write about. In response to his words, Sacramento fans used actual cow bells when the Kings were playing the Lakers. The matchup looked really promising, as these were the two best teams in the league. The Lakers were led by two superstars - center Shaquille O'Neal and shooting guard Kobe Bryant - while the Kings were a blend of great passers and shooters. In an article dedicated to the series all of the Kings' players talk about the chemistry and unselfishness of their teammates as the main reasons for their success (Abrams 2014).

After the first four games the series was even. The Lakers were constantly complaining about bad officiating throughout the series, but it escalated after Game Five. O'Neal's extraordinary size (7'1', $325 \mathrm{lb}$ ) was a double edged sword - with it he was able to basically push the opponents out of his way, but also because of that forceful style of play a lot of calls against him were not called. This was the case in Game Five, which the Lakers lost by just one point. After that game O'Neal complained about the referees, as he shot just one free throw and was ejected before the game's end for committing six fouls. As superstars usually get more friendly calls, it was obvious that referees would be more careful about his plays in the next game (Abrams 2014).

The Youtuber and blogger nicknamed "NFLranking" created a website and a video about the series, entitled: "The Greatest Tragedy in Sports." Sports reporter Ailene Voisin said: "Game 6 was the most poorly officiated big game that I've ever covered, and I started covering the league in ' 81 ", while columnist Michael Wilbon called the game "an abomination" (Abrams 2014). Still, both journalists claimed that it was rather a bad night of refereeing than a conspiracy that led to the outcome. Shaquille O'Neal calls himself "a big 'conspiracy theory' guy," but did not believe the accusations made by the Sacramento Kings and numerous NBA fans that the game was rigged (O'Neal 2011, p.154). He argues that the Lakers were able to win the game 
thanks to an exceptional free throw shooting night by an otherwise bad performer from the charity stripe himself. Throughout his career O'Neal made around half of his free throws, but in the series he largely improved his statistics. In Game Four O'Neal was nine of thirteen, in Game Five he shot just one, but in Game Six O'Neal executed 13 of 17. In the final game of the series Shaq made 11 of 15. It could be argued that if there actually was a conspiracy to allow the Lakers to win with the aid of free throws, a more reliable shooter would be sent to the line.

In the NBA there are three referees working on the court. During Game Six the group consisted of: Bob Delaney, Tom Bernhardt and Dick Bavetta. Knowing that Shaq shot just one free throw in the previous game, the Lakers' plan for the game was to get the Kings in foul trouble early. On the other hand, the Kings' center, Vlade Divac, used to "flop" - pretend that he was being fouled after making contact with the opposing player - to make the referees call offensive fouls on O'Neal. He succeeded in Game Five, as the Lakers center got in foul trouble fairly quickly, but after the complaints from the superstar, it was clear that this strategy would no longer work. Aware of that, O'Neal demanded the ball and drew contact on almost every play, intending to get calls against Divac and anyone else who was guarding him. Referee Bob Delaney admits: "we all knew Vlade flopped. We watched enough tape and we got so much better at it" (Abrams 2014). Even when the Kings' center was standing with his hands up, motionless, the referees used their whistles and called fouls against him. Still, according to a thorough analysis by Roland Beech: "the game started off with some breaks overall for the Kings and was very even at the half" (Beech 2008). On his website Beech analyses every call, made and missed. Until that part of the game the Lakers shot just 13 free throws, but both Kings' centers (Divac and Scott Pollard) had four fouls and risked getting ejected in the fourth quarter.

In the second minute of the fourth quarter the referees called a three-second violation against the Lakers, and the Kings players' initial reaction to the call says a lot about their mind state in the final part of the game: they thought that the referee called a foul against them, as they all looked at the official with bafflement. Just before, Pollard was ejected after two dubious calls, one on offence and one on defence. Both calls were made by Bob Delaney, who later claimed that by going through the tape the viewer will admit that there was actual contact on all plays (Abrams 2014). With 8:29 minutes left in the game, the referees called a foul on Divac, who was trying to stop O'Neal with both of his hands raised up. This did not look like a foul, and even if it was, similar 'fouls' were not called even at the beginning of the quarter. Beech observes that Bavetta's calls "did seem to tighten up in the fourth quarter...contact that he was letting go by without a whistle in the first three quarters suddenly seemed much more severe than contact getting whistles down the stretch" (Beech 2008). This was Divac's fifth foul, with the sixth coming in at 2:29 minutes until the end of the game. Kings' Chris Webber was the one that actually fouled Lakers' Robert Horry, but the referees missed that call. Just a second later Horry fell in front of Divac and the foul was called on the Sacramento center, as if to make up for the missed one. This would have been Webber's sixth foul if called correctly and Webber would be ejected from the game. Still, the fifth foul on Webber was also a bad call, as he was called for an offensive foul on Horry. In his analysis of the game Roland Beech refers to the call as "dubious," but it was just wrong, as it is clear that Horry's feet are not set as he flops after making contact with Webber. Beech notes four more dubious calls during the last 2:28 minutes of the game, all of them in Lakers' favour. The most controversial came at just 12 seconds left in the game, as Kobe Bryant hit Mike Bibby in the face with his elbow and the foul was called on the bleeding Sacramento point guard. Granted, Bibby was holding the Laker prior to the hit, but Bryant's action was left with no consequence. The Kings then committed two intentional fouls and lost the game by six points.

It must be noted that there were also a lot of correct calls made that night, and Beech observed "only" eight dubious ones throughout the game, but the issue here is that seven of them were made in Lakers' favour (Beech 2008). Donaghy claimed that two "company men" - officials held in high regard by the league because they made the games interesting with questionable calls whenever the need for such occurred - refereed during that game. He was talking about Bavetta and Delaney. Tom Bernhardt, the third referee, said years later: "I wasn't happy with the game. I wasn't happy with my partners as a whole" (Abrams 2014). He also adds that no conspiracy was involved - just a bad night by Bavetta and Delaney. This opinion is expressed by almost everybody involved, at least publicly, as the more notable participants are still employed by or their position 
is in some way tied to the NBA. The truth will probably never be known.

\section{Accusations, Controversies and the Spectacle}

The spectacle is all about representation. The accumulation of capital in regard to the spectacle is more about collecting notions and experiences than actual objects. This means that the true value of objects is assessed individually and depends on the personal connection of the individual to the object. Yet some connections are enforced by the so-called creators of the spectacle. In the case of sporting events, these creators are the league and team executives, as more revenue for the league means more profits for each team. To establish that connection the league prepares highlight reels, while teams organize giveaways and contests for fans in the arenas. Competition-wise, as the NBA season is 82 games long, it is hard to keep fans interested in each and every game, as what follows are the playoffs, in which, arguably the "real" competition begins. And as playoff series are seven games long, it is the last games, most preferably game sevens, where both teams are in a win-or-go-home situation, that are the most exciting to watch.

It is easy to understand why the NBA might as far as fixing the outcomes of games, since American professional leagues are constantly fighting for ratings. Higher ratings mean higher television and sponsorship deals, which mean more revenue for everybody involved, including the league, team owners, and the players. Professional leagues shy away from controversies as much as they can, since marketing the image is often more important than the actual product. "Understood on its own terms, the spectacle proclaims the predominance of appearances and asserts that all human life, which is to say all social life, is mere appearance" (Debord 1995, p. 14). The NBA must appear real in order to be real, not the other way round. What this means is that the notion of "realness" is crucial in contributing to the popularity of the league, even though this sort of realness is basically good marketing.

In his 2002 summary of the Kings-Lakers series journalist Bill Simmons examines controversial playoff games three years prior, when either the objective was to prevent the series from ending too soon or keep a big-market team in the playoffs (Simmons 2002). From the seven ones he mentions, four were elimination games officiated by Dick Bavetta. The referee was inducted into the Naismith Memorial Basketball Hall of Fame in 2015, a year after he retired. He officiated NBA games for thirty nine years. Former NBA referee Tim Donaghy argued that Bavetta was a genial NBA veteran and faithful company man who wanted to facilitate a quality entertainment product every night. Since fans generally find a close game more compelling, Bavetta made a deliberate effort to keep the contest competitive (Arnovitz 2009). Bavetta used to brag to other referees that he was the man NBA always chose for important games. Donaghy claimed that Bavetta also used to pride himself in keeping games interesting, especially when they involved an underdog (Arnovitz 2009). The referee's intentions were in agreement with the idea of the spectacle - he treated the game as a product, in which the most interesting outcome was more important than the fair one. From a marketing standpoint, Game Seven is always more interesting than Game Six. With both teams facing elimination, there is more pressure and excitement involved, making for more compelling television. The overwhelming emotions on the floor may lead to conflict between individual players, which in turn may lay ground for a rivalry. Rivalry makes for an interesting storyline, which in turn fuels and sustains the spectacle of modern professional sports.

Donaghy certainly had an insider's insight, as he himself was an NBA referee for thirteen years. In 2007 he was caught by the FBI when gambling on NBA games. Around 2003 he had run up a gambling debt he could not pay. In order to make up for it, Donaghy started providing information on about thirty to forty NBA games a season (Tuohy 2010, p. 132). Donaghy claimed that his group had an almost eighty percent success rate, while the referee himself did not "intentionally fix a single game" (Tuohy 2010, p. 133). Instead, he would bet on games officiated by other referees - for example in those assigned to Bavetta, Donaghy would often bet on the underdog. Donaghy claimed that Bavetta kept games close to provide an entertaining outcome, but the results of an investigation conducted by economist Joe Price prove that "far from making 70 percent, that strategy would have lost you 12 percent of your money. In other words, choosing at random would have given you a better chance at success" (Arnovitz 2009). Price analysed 42 games officiated by Bavetta in the 200307 period - a time in which Donaghy reportedly gave out insider information - "where the closing betting line 
was 10 points or greater. The big underdogs in those contests went 17-25 against the spread - a winning percentage of 40.1 percent" (Arnovitz 2009). In betting the underdog is a team or an athlete for whom the odds are higher.

This investigation problematizes Donaghy's accusations, but Donaghy did not officially name specific games. Price himself writes that the conclusions were reached by an analysis of box scores and play-by-play data, so it is also not clear if Bavetta was the referee that made the controversial calls. This had no influence over the outcomes of games, but could have had influence over Bavetta's position in the league, as "his tendency for keeping games close made him a favourite of the League" (Arnovitz 2009).

Donaghy's letter submitted by his attorney to the U.S. District Court in New York in 2008 reveals "information on how top executives of the NBA sought to manipulate games using referees to boost ticket sales and television ratings" (Sheridan 2008). Among those were stories about how "the league officials would tell referees that they should withhold calling technical fouls on certain star players" (Sheridan 2008). Such evidence might suggest that the referee review and ranking system is flawed. As the referees are Leagueemployed, so are the observers who are supposed to attend games anonymously and review the referee's work. Donaghy revealed that his colleagues "were aware of the observers and maintained good relations with them to receive positive reports" (Tuohy 2010, p. 227). The League did nothing to verify these reports. Donaghy himself was able to gain qualification to officiate NBA games and hide his gambling habit despite the "thorough" background check NBA referee-candidates are subject to - conducted inter alia by the Arkin Group, led by the former head of the CIA's worldwide operation. Donaghy enjoyed a thirteen-year career as an NBA official (Tuohy 2010, p. 131).

Unsurprisingly, his accusations seemed to confirm what some Kings players and fans believed - that they were sacrificed for the sake of the spectacle. It is important to note that if such fixing occurred, its intention was not to advance the Lakers, but to provide more entertainment to the fans. In the case study example, ensuring one more game of the Lakers facing the Kings would have provided more interest and spectacle than either team playing an inferior team in the finals. And while the truth will probably never come to light, because of the control NBA has over its employees and the legality thereof, there is no denying the entertainment value of the last game of the series.

\section{Conclusion}

Athletes get in trouble and fix games to avoid the consequences of their off-court actions. This applies especially to drug addicts and gamblers, who get into debt because of their habits (Tuohy 2010, p. 75). The same can be said about referees, who are also interested in providing outcomes that will favour them in the long run. Professional sports and gambling are inter-connected. Things like injury reports were at first only important from a gambling perspective, as they were supposed to inform betters about injuries to key players. This was prevented by an obligatory listing of injured players, implemented by the NFL (Tuohy 2010, p. 72). Nowadays gambling has moved a bit into the background, and what is more important is the spectacle. In 2012 San Antonio Spurs were fined $\$ 250,000$ for keeping secret a planned sitting of their four key players for a nationally televised game against their then-rivals, the Miami Heat. Then-commissioner David Stern claimed that "the Spurs' actions were in violation of a league policy [...] against resting players in a manner contrary to the best interests of the NBA" (Golliver 2012). As the coach cannot even handle his roster as he sees fit, it is probable that the league would be at least interested in rigging some of its games in order to make them more exciting for a casual fan.

Had the Kings won the 2002 Western Conference Finals, they would face off against the New Jersey Nets. The series would create a ratings nightmare of sorts for the NBA, as the league was still trying to cope with the loss of its biggest star, Michael Jordan (he was still in the league, but his Wizards did not make the playoffs during his two year "comeback tour"). The Nets eliminated the Boston Celtics in six games. The Celtics-Lakers rivalry is the biggest and most marketable in league history, so it should not come as a surprise if the league officials would push for both teams to meet once more in the most important series of the postseason. Since the NBA could not have that, it could at least have a new dynasty, which the Lakers would undoubtedly become after winning their third Finals in a row. 
With the Warriors' key player's suspension in the 2016 NBA Finals, it seems that the suspicions of gamefixing will not be silenced easily. Referring to the situation, Donaghy said that while he was refereeing in the NBA it was implied that officials should favour teams that were down in the series in order to prolong them, or at least make the games interesting. He also added that the player was not suspended for his offences during the Conference Finals with the Thunder because it was the Warriors who were down in the series (SI Wire 2016). If there was an actual problem in 2002, a situation like this proves that it has not gone away. Still, there will always be people looking for cracks in a system. The NBA is a great, entertaining league with world-class talent. It seems that there is no need for such controversial actions in order to keep it interesting for its regular fans. Yet highlight videos of incredible shots, dunks and passes are not enough to keep casual fans interested, at least for long. The society of the spectacle demands constant stimulation through exciting new content. As this type of spectatorship is not going away any time soon, outcomes still may be fabricated - or perceived as such - in order to keep the viewers satisfied.

\section{REFERENCES}

Abrams, J. (2014, May 7). All the Kings' Men. Grantland. Retrieved May 9, 2017, from: http://grantland.com/features/2002-western-conference-oral-history-los-angeles-lakers-sacramento-kings/

Arnovitz, K. (2009, Dec 8). Tim Donaghy's tale of Dick Bavetta, ESPN. Retrieved May 8, 2017, from: http://www.espn.com/blog/truehoop/post/_id/11341/tim-donaghys-tale-of-dick-bavetta

Aschoff, N. (2015). The New Prophets of Capital. London: Verso.

Beech, R. (2008). Reviewing the calls: Lakers-Kings Game 6. 82games.com. Retrieved May 9, 2017, from: http://www.82games.com/lakerskingsgame6.htm

Cary, T. (2015, June 12). Phil Jackson: 10 of His Worst Insults. Cheat Sheet. Retrieved May 7, 2017, from: http://www.cheatsheet.com/sports/10-of-phil-jacksons-most-famous-insults.html/?a=viewall

Dayton, W. (2010, May 12). The Lost Champions: The 2002 Sacramento Kings and the Fixed Western Conference Finals. Roundball Daily. Retrieved May 6, 2017, from: http://roundballdaily.com/2010/05/23/the-lost-champions-the-2002sacramento-kings-and-the-fixed-western-conference-finals/

Debord, G. (1990). Comments on the Society of the Spectacle London: Verso. (1995). Society of the Spectacle. New York: Zone Books.

Gaines, C. (2016, March 17). Only 5\% of Americans call the NBA their favorite sport. Business Insider. Retrieved May 9, 2017, from: http://www.businessinsider.com/most-popular-sports-in-the-us-2016-3?IR=T

Gallagher, M. (2012, June 6). The NBA's Greatest, Ugliest Series. The Daily Beast. Retrieved May 6, 2017, from: http://www.thedailybeast.com/articles/2012/06/06/the-nba-s-greatest-ugliest-series

Golliver, B. (2012, November 30). Spurs fined \$250K for resting players. Sports Illustrated. Retrieved May 10, 2017, from: https://www.si.com/nba/point-forward/2012/11/30/gregg-popovich-david-stern-spurs-fined-nba

Greil, M. (2002) The Long Walk of the Situationist International. In T. McDonough (Ed). Guy Debord and the Situationist International (pp. 1-20). Cambridge: The MIT Press.

Groves, R. (2015, Dec 12). Why The NBA Will Eventually Overtake The NFL In Popularity And Why It Matters. Forbes. Retrieved May 10, 2017, from: https://www.forbes.com/sites/rogergroves/2015/12/12/why-the-nba-will-eventuallyovertake-the-nfl-in-popularity-and-why-it-matters/\#242c3967e4c6

Kellner, D. (2001). The Sports Spectacle, Michael Jordan, and Nike: Unholy Alliance? In D. Andrews (Ed). Michael Jordan, Inc (pp. 37-64) New York: State University of New York Press.

The Wages of Wins Journal (2013, July 3). Is it legal for the NBA to rig games? The Wages of Wins Journal. Retrieved May 9, 2017, from: http://wagesofwins.com/2013/07/03/is-it-legal-for-the-nba-to-rig-games/

O’Neal, S. (2011). Shaq Uncut. New York: Grand Central Publishing.

O'Sullivan, D. (2016, June 13). Breaking Cleveland's Curse. Jacobin. Retrieved May 9, 2017, from: https://www.jacobinmag.com/2016/06/cleveland-cavaliers-cavs-nba-dan-gilbert/

Putterman, P. (2016, May 5). Chris Webber Believes Game 6 of 2002 Conference Finals was Fixed. Awful Announcing. Retrieved May 5, 2017, from: http://awfulannouncing.com/2016/chris-webber-believes-game-6-of-2002-conferencefinals-was-fixed.html

SI Wire (2016, June 13). Tim Donaghy: NBA suspended Draymond Green to prolong Finals. Sports Illustrated. Retrieved May 9, 2017, from: https://www.si.com/nba/2016/06/13/tim-donaghy-draymond-green-suspension-prolong-nba-finalswarriors-cavaliers 
Simmons, B. (2002). Only stupid question is one not asked. ESPN. Retrieved May 10, 2017, from: http://proxy.espn.com/espn/page2/story?page=simmons/020606

Sheridan, C. (2018, June 11). 2002 Lakers-Kings Game 6 at heart of Donaghy allegations. ESPN. Retrieved May 9, 2017 , from: http://www.espn.com/nba/news/story?id=3436401

Tuohy, B. (2010). The Fix Is In. Port Townsend: Feral House.

AUTHOR'S ADDRESS: $\quad$ Lukasz Muniowski

Institute of English Studies

Faculty of Modern Languages

University of Warsaw

ul. Krasińskiego 26/20

01-769 Warsaw, Poland

E-mail: lukasz.muniowski@gmail.com

Received: 26 November 2017; Accepted: 15 January 2018 